https://artnodes.uoc.edu

\title{
El futuro está por crear: temporalidad e imaginación en el Antropoceno
}

\section{Borja Muntadas}

Universitat Oberta de Catalunya

Alba Torrents

Universitat Oberta de Catalunya

Fecha de presentación: octubre de 2021

Fecha de aceptación: enero de 2022

Fecha de publicación: enero de 2022

\section{Cita recomendada}

Muntadas, Borja; Torrents,Alba. 2022. «El futuro está por crear: temporalidad e imaginación en el Antropoceno ». En: Garcés, Marina (coord.). «Ecología de la imaginación». Artnodes, no. 29. UOC. [Fecha de consulta: dd/mm/aa]. https://doi.org/10.7238/artnodes.v0i29.393021

\section{Resumen}

La noción de Antropoceno, introducida por Crutzen, ha planteado nuevas concepciones de la temporalidad y nuevas formas de entender la relación entre lo natural y lo humano. Chakrabarty, por ejemplo, en su artículo «The climate of history: four thesis», nos explica que nos encontramos en un momento en el que hay que poner en duda la distinción entre historia humana e historia natural y empezar a considerar al ser humano como agente de cambio geológico. De este modo, Chakrabarty cuestiona la linealidad del tiempo histórico y la posibilidad del progreso, al tiempo que mantiene una postura crítica con las concepciones filosóficas de la historicidad.

En este artículo exploraremos de forma crítica diferentes concepciones de la historicidad, la temporalidad y el cambio a la luz de la noción simondoniana de individuación, que nos permitirá imaginar otras formas de relación entre lo humano y lo natural. Nuestro propósito es presentar nuevas formas de 
entender la temporalidad alejadas de la visión lineal de la historia, donde el cambio es mera adición estática de una diferencia específica a un conjunto de características genéricas. Ante las críticas a la noción de Antropoceno, vemos que este nos permite problematizar la relación entre el individuo y su entorno, y nos permite imaginar un nuevo marco para afrontar la nueva situación de crisis ecológica del nuevo milenio. Entender las ecologías específicas restituyendo su temporalidad en un sentido profundo es necesario para comprender esta nueva perspectiva del «fin de mundo», es decir, como un cambio radical en las condiciones materiales de existencia de la especie humana.

\title{
Palabras clave
}

Antropoceno; historia; imaginación; agencia; futuro

\section{The future is yet to be created: temporality and imagination in the Anthropocene}

\begin{abstract}
The notion of Anthropocene, introduced by Crutzen, has posed new concepts of temporality and new ways to understand the relationship between the natural and the manmade. Chakrabarty, for example, in his article "The climate of history: four thesis" explains that we find ourselves at a point where we must cast doubt upon the distinction between human and natural history, and begin to consider mankind as an agent of geological change. In this way, Chakrabarty questions the linearity of historical time and the possibility of progress, while maintaining a critical stance on philosophical concepts of historicity.

In this article, we will critically explore different concepts of historicity, temporality, and shift towards a simondonian notion of individuation, which will enable us to imagine other types of relationship between the manmade and the natural. Our aim is to present new ways of understanding temporality outside of a linear view of history, where change is a mere static addition of a specific difference to a set of generic characteristics. Faced with critics of the Anthropocene notion, we can see that this enables us to problematize the relationship between an individual and their surroundings and allows us to imagine a new framework for tackling the ecological crisis of the new millennium. Understanding the specific ecologies by restoring their temporality in a deep sense is necessary in order to understand this new "end of the world" perspective, that is, as a radical change in the material conditions of the existence of the human species.
\end{abstract}

\section{Keywords}

imagination, sympathy, perspective-taking, mental representation 


\section{artnodes}

https://artnodes.uoc.edu

El futuro está por crear: temporalidad e imaginación en el Antropoceno

\section{Introducción}

Cuando en el año 2000 Paul J. Crutzen y F. Stoermer acuñaron el término Antropoceno, difícilmente se hubieran podido imaginar la enorme trascendencia que iba a tener el término. Dos décadas después, el impacto del Antropoceno está lejos de desaparecer y se ha convertido en un tema transdisciplinar, que va más allá de la clásica distinción entre ciencias naturales y ciencias humanas. El concepto de Antropoceno cristaliza a principios del siglo XXI como resultado de diferentes estudios sobre el cambio climático que se vienen elaborando desde mediados del siglo XX. Las evidencias empíricas del Antropoceno muestran que el impacto de la acción humana sobre el planeta abarca gran parte de las geoesferas terrestres, por lo que el Antropoceno puede concebirse como una crisis global del ecosistema. Pero más allá de este impacto, que se ha visto acelerado en los últimos años, el debate alrededor del Antropoceno, ha puesto en evidencia la urgencia de rearticular las tesis sobre las relaciones entre lo humano y lo natural en los discursos sobre la historia: ¿Quién 0 qué es agente de transformación histórica y qué significa la agencia en estos procesos de transformación? ¿Cuál es el papel del medio natural en la acción humana? ¿Qué papel juega lo colectivo en relación con la acción y experiencia individual? ¿Qué impacto puede tener sobre nuestro presente imaginar el futuro tras el colapso? ¿Qué papel puede jugar la imaginación cuando esta, tras décadas de exaltación creativa, está agotada? ¿Qué mundo podemos imaginar cuando el colapso está presente y la catástrofe lo estará en un futuro demasiado cercano?

Dipesh Chakrabarty publicó en 2009 el conocido artículo «The Climate of History: four theses", en el que describe la transformación de nuestra especie de simple agente biológico a fuerza geológica. La colisión de los humanos con la Tierra contribuyó al desmoronamiento de una distinción que era esencial para la episteme moderna: la distinción entre naturaleza e historia, separados desde el siglo XVIII por una doble discontinuidad. Dentro de la tradición filosófica occidental de comienzos del siglo XVIII se abren diferentes interpretaciones sobre la historicidad. Una de las ficciones más importantes, y que más ha marcado nuestra forma de comprender el devenir histórico, son las que van de Vico a Groce, en las que encontramos una clara separación entre naturaleza e historia. Tras esta ficción ontológica, fuertemente sustancialista, el criterio para considerar un fenómeno histórico es el de «interioridad». Así, al desproveer a la naturaleza de este atributo, se le sustraía también el de historicidad: solo transforman los humanos y la naturaleza sirve como exterioridad o materia.

Arendt presenta una crítica a esta ruptura insalvable entre lo natural y lo histórico en su artículo «The concept of History: Ancient and Modern» (Arendt 1961), donde pone en cuestión la distinción entre historia humana e historia natural a partir de los conceptos de proceso y tecnología. Estos le sirven de puente para unir naturaleza y acción humana («agencia») 0 historia: de la misma manera que el ser humano es capaz de iniciar procesos sociales en la historia, también lo es de iniciar procesos naturales impredecibles, y lo hace gracias a la tecnología. Compartimos con Arendt la convicción de que existe una continuidad entre naturaleza e historia. Ahora bien, su propuesta, que hunde sus raíces en la filosofía de Aristóteles -principalmente en la Política y el De Anima-, parte de cierto antropocentrismo y comparte tesis fundamentales del hilemorfismo, las cuales, a nuestro parecer, oscurecen el carácter relacional de la realidad. Su propuesta es antropocéntrica porque hace que la naturaleza se comporte de forma humana tras haber intervenido sobre ella. Si bien Arendt recupera la continuidad entre naturaleza e historia, no llega a afirmar en ningún momento que tal distinción se proyecte desde una ficción ontológica y antropológica. La propuesta de Simondon, al contrario, plantea una postura antisustancialista y radicalmente relacional. A partir de sus tesis podemos criticar la clara distinción entre naturaleza e historia que se plantean desde la filosofía de la historia. De la obra de Simondon se puede extraer un argumento poderoso en contra de la discontinuidad entre historia natural e historia humana, ya que encontramos articulada una interioridad de lo no humano anterior a su intervención industrial en el siglo XVIII. La propuesta de Simondon es poderosa, ya que nos permite imaginar la relación humano-naturaleza más allá de la ficción moderna que sitúa uno frente a otro, y que nos aboca a lógicas del colapso y la catástrofe. La potencia del pensamiento de Simondon nos permite reimaginar, desde otros lugares, nuestra relación con el medio.

\section{Antropoceno: historia, acción humana y medio}

El cambio climático se presenta como un problema urgente, que reclama soluciones globales a largo plazo y que, tal y como afirma Serres, amenaza la existencia digna y humana sobre la tierra de futuras generaciones (Serres 1995, 6-7). Como defiende Marina Garcés, nos encontramos ante la catástrofe del tiempo histórico (Garcés 2017, 25). La crisis ecológica no solo hace tambalear la esperanza de un futuro digno, sino que hace replantear el sentido de la propia historicidad. En el año 2009, el historiador D. Chakrabarty puso en el centro del debate político e intelectual estas cuestiones hasta la fecha ajenas entre sí en un artículo publicado en Critical Inquiry. cambio climático e historia. La tesis central del artículo sostenía que nuestro sentido histórico del presente se ha convertido en algo profundamente destructivo, en lo que se refiere al significado de la historia y del futuro más cercano. Como en los relatos de ciencia ficción, nunca había estado tan cerca un futuro apocalíptico.

La mayoría de las discusiones públicas sobre el calentamiento global se iniciaron a finales de los ochenta y principios de los noventa del 


\section{artnodes}

https://artnodes.uoc.edu

El futuro está por crear: temporalidad e imaginación en el Antropoceno

pasado siglo, ${ }^{1}$ el mismo periodo en el que los científicos sociales y los humanistas comenzaron a discutir sobre la globalización. Sin embargo, no fue hasta la década del 2000 cuando el debate se intensificó. Entonces el problema se transformó en una cuestión política inaplazable.

La primera de las tesis que plantea Chakrabarty es el cuestionamiento de la rígida separación entre historia humana e historia natural que tiene sus orígenes en las filosofías de la historia del siglo XVIII. De acuerdo con los diferentes análisis que hace Löwith de las diferentes filosofías de la historia, por una clara influencia del idealismo de Croce, del historicismo de Dilthey y del pensamiento de Vico, la historia ha sido considerada algo radicalmente distinto de la naturaleza. Incluso la ciencia natural ha sido concebida como una construcción plenamente humana: más que aprender la naturaleza lo que hace es comprender nuevamente lo humano (Löwith 1949, 148). Así, Ios discursos de la historicidad consideraban que la naturaleza únicamente tiene historia porque hay una acción humana intencional sobre esta. Por ejemplo, según el historiador John Bury, los cambios que se producen en el terreno de lo humano y lo social son más rápidos y acelerados que las transformaciones del entorno «natural», que son tan lentas y repetitivas que parecen atemporales, por no decir inexistentes (Bury 2008, 17).

Para Chakrabarty, esta discontinuidad entre temporalidad natural y temporalidad humana ha sufrido un colapso en la era del Antropoceno. Una de las críticas principales de Chakrabarty es que todos estos planteamientos no tuvieron en cuenta la idea extendida en la literatura de que el clima y el ecosistema global a veces pueden llegar a un punto de inflexión en el que ese lento y aparentemente intemporal trasfondo del medio natural se transforma a tal velocidad que solo puede significar una catástrofe para los seres humanos (Chakrabarty 2009). Esta nueva conciencia ha puesto en duda la antigua distinción entre historia natural y humana, y la mayoría de los científicos del clima afirman que el ser humano no es un simple agente biológico, sino que ejerce ahora como fuerza geológica. Durante mucho tiempo se pensó que la cronología humana era insignificante en comparación con la intensidad y la fuerza de los procesos geológicos, y que el agotamiento de los recursos naturales era impensable (Soriano 2021, 13-34). Quizás hubo un tiempo en que fuera así, pero la aceleración industrial y el impacto de las actividades humanas sobre el medioambiente han hecho que dejemos esa era atrás.

$Y$ ahora que somos plenamente conscientes de que los humanos somos una fuerza de la naturaleza en sentido geológico, los principios fundamentales del pensamiento político tradicional se han desmoronado. Según el filósofo Yuk Hui, el concepto de Antropoceno es un acontecimiento límite en lugar de una nueva era geológica. Así, para Hui, el Antropoceno es una de tantas crisis en las que la Modernidad se cuestiona a sí misma (Hui 2017), lo que nos muestra de forma clara y evidente la continuidad entre lo humano y lo natural bajo la forma de una catástrofe ecológica global.

\section{Ecología política y catástrofe}

El concepto de Antropoceno que define Chakrabarty hunde sus raíces en esta reflexión: el ser humano fabrica la naturaleza que habita de la misma forma que fabrica la historia como proceso (Arendt 1961). Arendt analiza esta noción de historia como proceso en Between Past and Future (1961). El texto de Arendt «The concept of History: Ancient and Modern» puede leerse como una relectura del concepto de acción tal y como años antes lo plantea en La condición humana (Arendt 1998). Dicho de otra forma, Arendt se ve en la obligación de reformular y matizar el concepto de acción humana que años antes había elaborado ampliamente en La condición humana. ¿Qué es para Arendt la acción? Actuar significa tomar una iniciativa, comenzar o poner algo en movimiento, sin embargo, este comienzo no es el mismo que el que se da en el mundo; no es el comienzo de algo, sino de alguien. Con el ser humano el principio del comienzo entra de lleno en el mundo, y con él el principio de libertad. La propia naturaleza del comienzo de algo implica la aparición de lo absolutamente nuevo (Arendt 1998, 178).

A principios de los años sesenta, Arendt es plenamente consciente del impacto que pueden causar, a medio y largo plazo, tanto la energía nuclear como la de combustibles fósiles. Uno de los ejes principales del pensamiento político de Arendt es la capacidad de acción del ser humano. La acción que se caracteriza por su carácter impredecible, iniciando procesos que transforman tanto la sociedad como el curso de la historia. Bajo el concepto de proceso subyace el concepto de acción (Arendt 1998, 230-36). Consciente del impacto que puede llegar a tener la tecnología sobre el medio ambiente, sostiene que lo humano proyecta sobre la naturaleza su propia capacidad de acción. En este sentido, la naturaleza adquiere capacidad de actuar de modo parecido al ser humano, ya que es capaz de iniciar procesos inesperados e improbables (Arendt 1998, 232). La acción desencadena una nueva cadena de acontecimientos totalmente impredecible. Por eso el ser humano es incapaz de controlarla con anticipación. La capacidad humana para la acción ha comenzado a dominar sobre todas las demás. Según Arendt (1961, 60-61), si al iniciar procesos naturales comenzamos a actuar sobre la naturaleza, como lo hacíamos sobre la historia, hemos comenzado a proyectar sobre ella el carácter propio de la impredecibilidad humana, cuando creíamos que la naturaleza funcionaba bajo leyes estables e inmutables. Así, hemos proyectado el carácter político de la acción humana sobre la naturaleza. Esta reflexión pone en el centro la cuestión de la continuidad entre lo humano y lo natural a través de la proyección humana sobre la naturaleza a partir de la tecnología, distanciándose de los planteamientos clásicos de las ciencias del espíritu y de las filosofías de la historia como las de Vico o Croce.

Un segundo punto que se puede extraer del planteamiento de Arendt es que el creciente desarrollo industrial marca un punto de inflexión

1. Conferencia de Naciones Unidas sobre el Medio Ambiente y Desarrollo, realizada en 1992 en Río de Janeiro, o bien la firma de los acuerdos de Kioto en 1997. 


\section{artnodes}

https://artnodes.uoc.edu

El futuro está por crear: temporalidad e imaginación en el Antropoceno

extraordinario: la naturaleza no solo dispone de capacidad de agencia gracias a la proyección humana, sino que los procesos que se inician en el medio ambiente se caracterizan por su irreversibilidad. En definitiva, el ser humano, tras proyectar su capacidad de acción, provoca que los procesos naturales sean a la vez impredecibles e imprevisibles, y que, por tanto, escapen al control humano. En consecuencia, la clara distinción entre naturaleza e historia, que se defiende desde el historicismo tradicional, carece de sentido, porque sabemos que somos capaces de iniciar procesos nuevos e impredecibles tanto en una como en otra. Entonces, según Arendt, el ser humano debilita la capacidad predictiva de la ciencia desde el mismo momento en el que actúa sobre la naturaleza. Así pues, la capacidad de agencia natural se independiza de la agencia humana.

Ambas lecturas pueden sernos útiles. La propuesta de Chakrabarty, que hemos expuesto más arriba, que pone en cuestión la distinción entre historia natural e historia humana a partir de la noción de proceso, hunde sus raíces en la propuesta de Arendt. A su vez Isabelle Stengers, Danowski y Viveiros de Castro se acercan a la visión de Löwith en su lectura catastrófica: el pasado y el presente, son la condena del futuro. El concepto de historia está construido sobre el supuesto de que pasado, presente y futuro están conectados bajo una cierta idea de continuidad de la experiencia humana. Hoy nuestro presente abre un sinfín de preocupaciones sobre nuestro futuro. Esas preocupaciones tienen su origen en la propia acción humana, tal y como la ha definido Arendt.

No cabe duda de que existe consenso científico acerca de que el hombre es el responsable de la crisis actual del cambio climático (Soriano 2021, 14-27). Dicho esto, la antigua distinción humanista entre historia natural e historia humana ha dejado de ser útil. Consideramos que tanto el colapso temporal como espacial ponen de relieve la convergencia crítica entre los ritmos de la naturaleza y de la cultura. De acuerdo con Viveiros y Danowski, el tiempo histórico vuelve a entrar en resonancia con el tiempo ecológico (Danowski y Viveiros de Castro 2019, 23-29) La especie humana corre el riesgo de colisionar espectacularmente contra un muro que ella misma ha construido, a fuerza de progreso industrial y desarrollo económico desigual. La propuesta es clara: inseparabilidad entre lo humano y lo ambiental. Por eso, es necesario y urgente poner en el centro del debate actual la construcción de una nueva ecología dispuesta a medirse con el desastre y el colapso. Para ello, necesitamos comprender qué significa el término ecología. Plantearemos esta cuestión a partir de la lectura de Simondon.

\section{Crítica a la distinción entre historia humana y natural desde Simondon}

La cuestión de la unidad de las ciencias humanas debe ser replanteada nuevamente, donde las ciencias de la naturaleza inciten a un acer- camiento hacia lo real que englobe la antropología. No encontramos nada en la naturaleza que posea un estado separado, es decir, ninguna ciencia tiene un origen inmaculado y el nivel antropológico ya no puede ser considerado como un régimen aparte en la naturaleza, ya que en él hay implicadas problemáticas físicas, vitales, psíquicas y colectivas.

La forma en que Simondon desarrolla su filosofía de la naturaleza nos permite entender esta relación y continuidad no solo accidental -como sostienen quienes afirman que el Antropoceno marca un punto de inflexión en la historia geológica- entre lo humano y lo natural, lo físico y lo viviente, lo cultural y lo técnico. La filosofía de la naturaleza simondoniana se fundamenta en una concepción plurívoca del ser, que da cuenta de todas las dimensiones de la realidad en su concretización. Su concepción ontológica viene marcada por un rechazo al hilemorfismo aristotélico; ${ }^{2}$ esta no da cuenta del devenir del ser al concebir la adquisición de forma del ente como algo ya producido, como un individuo ya consumado, y no como un proceso. Para Simondon, la filosofía ha abordado el problema del individuo como si este fuera siempre algo ya constituido, cuando, de hecho, el principio de individuación no puede ser postulado con anterioridad a la propia individuación: el individuo debe ser comprendido y explicado a través de la propia individuación, es decir, de forma ontogenética. El problema para Simondon es que al utilizar la lógica inductiva y pasar de un particular a un general (abstracción universal) se invisibilizan aquellos componentes que acontecen en el intercambio operacional tecnológico y se oculte el dinamismo fundamental de la operación.

La tarea simondoniana consiste, pues, en dar cuenta del carácter ontogenético, inventivo, múltiple y relacional de la realidad. Ontogenético, porque designa la aparición de los diferentes dominios de la individuación, la resolución creativa de problemáticas y la adquisición de forma que resultan de ella; inventivo, porque se trata de un ser dinámico y en constante transformación; múltiple, porque toma en cuenta todas las dimensiones de la realidad: la física, la vital, la psíquica y la colectiva; y finalmente, relacional, porque considera que la relación es constitutiva de la transformación del individuo, esta no es un mero añadido a los términos sino que tiene valor de ser; el individuo es teatro y agente de una actividad relacional que se perpetúa en él. En efecto, Simondon hace de su filosofía de la individuación una metafísica del devenir de los regímenes de realidad.

\section{Filosofía de la historia, agencialidad y relación}

Aunque Simondon no trató específicamente la cuestión de la historia, hay elementos de su filosofía que ponen en duda muchos aspectos ontológicos implícitos de las explicaciones del devenir histórico, del papel de la acción y la imaginación humana y su relación con la naturaleza.

2. La teoría de la adquisición de forma aristotélica, para Simondon, cae en el error epistemológico de concebir la materia y la forma como elementos abstractos, al ignorar y despreciar lo que realmente ocurre al fabricar un objeto concreto. 


\section{artnodes}

https://artnodes.uoc.edu

El futuro está por crear: temporalidad e imaginación en el Antropoceno

Según nos explica Chakrabarty y según hemos explicado en el apartado anterior, hay un cierto idealismo en la comprensión histórica actual, que encuentra sus raíces en la línea de interpretación Vico-Croce-Collingwood. Según esta línea interpretativa no hay distinción, en la naturaleza, entre el interior y el exterior de un acontecimiento; es decir, no hay propiamente una agencia, a diferencia del devenir histórico humano, de aquello que acontece en la naturaleza. Así, con Vico y Croce, se produjo una ruptura entre la explicación del devenir natural y del devenir histórico: solo lo humano puede ser estudiado como propiamente histórico, ya que la naturaleza carece de historicidad. Esta concepción implica una tesis antropocéntrica, que amplía la brecha entre lo humano y lo natural.

El pensamiento de Simondon nos es muy útil aquí para contrarrestar este dualismo antropocéntrico, tan arraigado en la filosofía de la historia que critica Chakrabarty y que mostramos en este artículo. En primer lugar, Simondon pone en evidencia los límites del discurso antropocéntrico, mostrando aquello que les falta a las ciencias humanas desde el punto de vista de la filosofía de la naturaleza. Al abandonar una lógica demasiado abstracta, en la que los procesos (naturales y físicos) están desprovistos de interioridad, Simondon muestra cómo lo intrínseco y extrínseco se deben tomar siempre como polos en un continuo de una relación. En realidad, lo que es el individuo, cualquier individuo, es esta relación, y su interioridad existe en tanto que operación relacional de una individuación que la engloba. El individuo es realidad de una relación constituyente, no interioridad de un término constituido. Con esta formulación no solo se abandona una concepción alejada del antropocentrismo de Croce y Vico, en el que únicamente el ser humano posee interioridad, sino que señala las trampas sustancialistas de ciertas visiones demasiado dualistas que no tienen en cuenta la realidad de la relación.

En segundo lugar, da agencialidad a los procesos naturales y técnicos sin caer ni en un naturalismo simple, ni en una tecnofilia parecida a la de ciertos transhumanismos o el aceleracionismo. Tal y como nos muestra Simondon, encontramos un antagonismo entre la cultura y la técnica. ${ }^{3}$ Su libro El modo de existencia de los objetos técnicos comienza con una denuncia: la cultura ignora en la realidad técnica una realidad humana. El antagonismo aparente entre lo técnico y lo humano proviene de una mala interpretación de lo que es la realidad técnica, que lleva a actitudes parecidas a la xenofobia (Simondon 2007, 31). Esta ignorancia humana aparta el objeto técnico del mundo de las significaciones, dándole solo una función de instrumental. Vemos, por un lado, cómo se ha imaginado la máquina desprovista de interioridad y, por el otro, cómo se ha velado el conjunto de la realidad técnica, porque se ha fragmentado hasta tal punto que no entendemos cuál es su funcionamiento en su totalidad. En su libro Invención e Imaginación, Simondon tratará el papel de la imaginación en relación con la tecnicidad, y situará la imagen como elemento infraindividual: la imaginación es una operación que atraviesa la subjetividad y la objetividad, y que se encuentran en el territorio de la colectividad (Simondon 2013, 13). La imaginación resulta en la resolución de las problemáticas individuo-entorno, mientras que la imagen tiene un carácter intermedio que funciona como realidad reguladora.

Este tipo de mentalidad dirigida a la tecnicidad, que Simondon compara con la xenofobia, es análoga a la que encontramos en el naturalismo. ${ }^{4}$ La postura naturalista, que para Hui es una de las posturas dominantes de la Modernidad (Hui 2017, 119), parte de una oposición entre naturaleza y cultura, que se traduce en una división jerárquica entre aquello humano y aquello no humano. Lo humano y cultural participan de lo no humano y lo natural, bajo formas de dominación. Como comenta Hui, la división humano-no humano se caracteriza por su continuidad física, pero por una discontinuidad espiritual (Hui 2017, 118). De nuevo, encontramos un sustancialismo en el posicionamiento naturalista que ignora lo real de la relación y sustrae la temporalidad a toda forma de existencia.

Vemos diferentes implicaciones importantes en la concepción filosófica de Simondon, cuando este autor sustituye el ser-sustancia por la ontogénesis. Es la propia génesis de lo real la que produce a los individuos; es decir, no son los individuos -ya formados- los que constituyen lo real. Este tipo de visión, donde hay una dependencia de la fundación de lo real a individuos ya constituidos, cae habitualmente en formas de subjetivismo e idealismo donde la agencia se vincula a un atributo, en la mayoría de los casos, humano. Pero en la ontogénesis simondoniana la agencia no puede ser un «atributo» del ser humano, sino que es constitutiva del propio proceso de individuación. Así, pasamos de un modelo en el que existe algo que se transforma o cambia (una materia pasiva) a causa de la acción singular de uno o muchos individuos (una forma activa), a otro modelo donde aparece un proceso, en el que las características de lo transformado tienen un papel activo en el conjunto de la transformación.

En el caso de la historicidad, esta perspectiva nos ayuda a entender los fenómenos históricos donde hay implicados determinantes culturales, tecnológicos, políticos, geográficos y biológicos, sin caer en un determinismo. Para esto, se deben tener en cuenta los aspectos materiales y específicos de producción de lo que se quiere analizar, sin dejar de lado los aspectos multifactoriales que configuran un elemento, ni reduciendo a un solo aspecto su explicación. Es interesante mencionar aquí el papel de la imaginación en el devenir social, cultural e histórico; la imagen, por el hecho de tener un carácter intermediario,

3. Aunque Hui nos comenta en su artículo que hay una menor reconciliación entre la naturaleza y la técnica que entre la técnica y la cultura (Hui 2017), si nos fijamos en el conjunto de su obra se da contestación y explicación a ambos antagonismos (aunque el primero menos explícitamente que el segundo).

4. El propio Aristóteles fue quien por vez primera criticó en su Poética el uso de máquinas para suspender a personajes en el aire, afirmando que la resolución de la trama debía resultar de la historia en sí misma, considerando así como mediocres todas aquellas obras que empleasen máquinas como recurso dramático (Rauning 2010, 43). 


\section{artnodes}

https://artnodes.uoc.edu

El futuro está por crear: temporalidad e imaginación en el Antropoceno

es fundamental en la resolución de problemáticas donde aparecen situaciones en el que existen incompatibilidades en diferentes niveles (físicos, vitales, psíquicos). Esta resolución no debe plantearse nunca de forma plenamente determinista, ya que caeríamos en el error de ignorar que el individuo solo es individuo en tanto que se mantiene, en el presente, el encuentro entre unas condiciones formales y unas condiciones materiales. ${ }^{5}$

Así, la comunicación entre niveles de realidad no se da, en Simondon, como entre entes ya constituidos de los cuales deriva una relación. De la misma manera, la relación entre el individuo y el medio no es nunca meramente accidental: el individuo es aquello nunca acabado, que conlleva un proceso activo y dinámico en el cual se constituye de forma conjunta con su medio. Para que se dé un proceso de individuación es necesaria una condición mínima de diferencia energética que implica un potencial de transformación de un sistema inestable. El concepto de preindividual aquí es de vital importancia: se trata de aquella realidad «sobrante» de un nivel de individuación que permite la aparición de otra dimensión de la realidad. El nivel preindividual, que en algunos casos se identifica con la energía potencial, es aquello destinado a dar cuenta de la ontogénesis y los sistemas de individuación. El ser preindividual corresponde tanto al individuo como al medio: ya que ambos se definirán a medida que se vayan constituyendo. Es decir, al ser lo preindividual aquello indeterminado, «aún por definir» no le corresponde ponerse ni del lado del individuo ni del medio; en tanto que indeterminado corresponde tanto a los dos como a ninguno.

Vemos cómo en el contexto del Antropoceno es importante rescatar el concepto de preindividual, ya que da cuenta tanto de la relación específica del par individuo-medio como del error de considerar al ser humano como algo distinto de la naturaleza, o como productor o deudor de esta: no son ni dos substancias distintas ni dos categorías separadas. Por lo tanto, una no puede producir a la otra. Cuando consideramos la naturaleza como algo anterior a lo ya individualizado, debemos entenderlo en el contexto de la ontogénesis y no desde una perspectiva teleológica: el individuo solo no puede ser deudor de su propia naturaleza, él no es el único producto de su actividad. Además, el papel de la imagen en el par individuo-medio, mediante la invención y la técnica, da cuenta del carácter también relacional que tiene la imaginación: la imagen, según Simondon, se encuentra en un nivel infraindividual en el que se hace evidente la porosidad de las relaciones interindividuales. A través de la génesis de la imagen, y la imaginación en general, se reticulan, a partir de esquemas técnicos, las relaciones individuo-entorno. Pero la imaginación nunca funciona a nivel cognitivo como un mero contenido de la consciencia, sino que es la forma en que la colectividad se relaciona con el entorno. Es decir, el individuo no puede dar cuenta de sí mismo a partir de sí mismo, ni tampoco puede considerarse una unidad que produce ella sola otro tipo de realidad, porque no es el todo del ser. Para entender al individuo debe considerarse un medio en relación continua con el individuo. Desde una perspectiva ontológica, la naturaleza es anterior al ser ya individualizado; a este le sucede una segunda individuación cuando se dan ciertas condiciones.

El marco ontoepistemológico simondoniano, pues, nos plantea un nuevo esquema en el que no solo el medio natural tiene un papel activo en las transformaciones del devenir humano (y no humano), sino que plantea una forma distinta de entender lo colectivo; pero no como un mero añadido de individualidades, sino como algo ontológicamente anterior al individuo ya constituido. Esta visión nos permite entender toda experiencia, incluida la experiencia histórica, su relación con el futuro y el papel de la imaginación, desde un punto de vista menos individualista y donde tanto lo colectivo como el medio tienen un papel fundacional.

\section{Conclusiones: sobre cómo imaginar el fin del mundo}

No solo las repetidas crisis económicas, políticas y medioambientales muestran este colapso a nivel global, sino que es la propia imaginación, tras encerrarla en el individuo, la que, por agotamiento, sufre un colapso tal que le impide pensar 0 imaginar un futuro que no replique el presente ni la extinción de la humanidad. La catástrofe no es el futuro apocalíptico que cae sobre la humanidad y el mundo, aplastándolos, sino la proyección de un presente sin porvenir sobre el futuro. La catástrofe es el futuro aplastado por las lógicas y las dinámicas del presente. Es el agotamiento de la imaginación que se sabe fracasada e impotente. Imaginar significa poder vincularse con horizontes que nos son extraños. «Imaginar es dar lugar a todo lo que aún no es y a los que están por llegar» (Garcés 2020, 67).

No hay duda de que hoy ya no creemos en el futuro de la misma manera que lo hicimos en la Modernidad. Vico y Croce creyeron que se podía confiar en el futuro y en el progreso: esperaban del futuro la realización de las promesas del presente. El futuro tenía dos características tranquilizadoras: primero, era cognoscible, ya que las tendencias inscritas en la historia eran predecibles, porque se desplegaban según líneas de crecimiento lineales y la ciencia histórica podía formular las leyes del desarrollo de la historia humana. Segundo, el futuro era modificable por parte de la voluntad humana, gracias a la técnica, la ciencia y la política (Berardi 2014, 113). El concepto de Antropoceno pone en crisis la cosmovisión moderna sobre el futuro. El medio natural no es una realidad subyugada a to humano: es aquello que se modifica y se define de forma coextensiva con lo humano. El futuro de la humanidad, por lo tanto, no puede ir desconectado de su medio. A partir de los años setenta el imaginario utópico de la Modernidad se transforma en distopía. La literatura y el cine de ciencia ficción fueron el laboratorio

5. Es decir, una comunicación a través de órdenes a partir de la amplificación de la información aportada por una singularidad. 
de este giro. A finales del siglo xx surge un imaginario donde el futuro desaparece, donde el tiempo se aplana hasta reducirse a un eterno presente. No creemos que el futuro esté a la altura de las expectativas que la Modernidad nos legó, pero no se trata de negar la existencia del futuro, sino la correspondencia entre futuro, progreso y bienestar a nivel global.

Todo pensamiento que nos lleve a imaginar un fin del mundo plantea la cuestión del comienzo y del fin: nos plantea nuestra relación con el final, no solo a nivel individual, sino también a nivel colectivo. Danowski y Viveiros de Castro hablan de la desaparición ontológica del tiempo (2019, 23-51). Pero más que sumarnos a una lógica teleológica de la catástrofe, donde el mundo es presentado en sí mismo en su fase última de extinción, nuestra crítica se dirige aquí hacia dos tendencias derivadas de la Modernidad y del naturalismo: un pensamiento que en sí mismo elimina el mundo antes del fin, y que ante la más que cercana y evidente posibilidad del colapso se rinde ante la catástrofe; y otro que niega la responsabilidad colectiva y la futura convivencia con la crisis medioambiental. Descartando la existencia de lo colectivo y la complejidad de todos los sistemas, del físico al social, y suprimiendo su continuidad ontológica, se obstaculiza la posibilidad de seguir con el problema, al decir de Haraway (2019). Así, la cuestión no es cómo resolvemos el problema de una vez por todas, sino cómo empezamos a situarnos en las problemáticas específicas de cada modo de existencia que garanticen el bienestar a nivel colectivo e individual.

Como afirma Marina Garcés, el tiempo en el que aún podemos intervenir sobre nuestras condiciones de vida se agota. Quizás hayamos dejado atrás la posmodernidad, que relegó el futuro a un presente eterno, pero hoy nos encontramos ante la experiencia del final, esto es, de la condición póstuma. Condición póstuma significa que nos encontramos en un tiempo de prórroga y que hemos aceptado la posibilidad de su propio final. El fin de los tiempos es el síntoma del agotamiento individual de la imaginación. «Condición póstuma» significa la muerte, no real, sino la muerte del tiempo histórico, producida por el relato dominante de nuestro tiempo (Garcés 2017, 16, 25). No se trata de despertar la imaginación en un juego de imágenes y posibilidades infinitas, sino empezar a comprender los fenómenos y las problemáticas éticas desde una óptica relacional, a partir de la propuesta de Simondon, en la que varios niveles de realidad están involucrados en su génesis. Proponemos la construcción de una ecología de la imaginación, en la que la creación de posibles permita establecer líneas de fuga en el presente con las que lo colectivo e individual puedan vibrar a un mismo ritmo, evitando la saturación y el colapso. Estas líneas de fuga deben configurarse en la génesis de una ética colectiva, porque la ética es la invención de relaciones entre vidas que conviven.

\section{Referencias bibliográficas}

Arendt, Hannah. Between Past and Future. Six Exercise in Political Thought. New York: The Viking Press, 1961.

Arendt, Hannah. The Human Condition. Chicago: The University of Chicago Press, 1998.

Berardi, Franco. Después Del Futuro. Desde El Futurismo al Cyberpunk. El Agotamiento de La Modernidad. Madrid: Enclave, 2014. Berardi, Franco. Futurabilidad. Buenos Aires: Caja Negra, 2017.

Bury, John. The Idea of Progress. An Inquiry Into Its Origin And Growth. Nueva York: Cosimo Classics, 2008.

Chakrabarty, Dipesh. «The Climate of History: Four Theses.» Critical Inquiry (2009). DOI: https://doi.org/10.1086/596640.

Danowski, Deborah; Viveiros de Castro, Eduardo. ¿Hay Un Mundo Por Venir? Ensayo Sobre Los Miedos y Los Fines, vol. 23. Buenos Aires: Caja Negra, 2019.

Garcés, Marina. Nueva llustración Radical. Barcelona:Anagrama, 2017.

Garcés, Marina. Escuela de Aprendices. Barcelona: Galaxia Gutenberg, 2020.

Haraway, Donna. Seguir con el problema. Bilbao: Consonni, 2019.

Hui, Yuk. «0n Cosmotechnics: For a Renewed Relation between Technology and Nature in the Anthropocene.» Techné: Research in Philosophy and Technology (2017). D0l: https://doi. org/10.5840/techne201711876

Löwith, Karl. Meaning in History. The Theological Implications of the Philosophy of History. Chicago: Phoenix Books-The University Chicago Press, 1949.

Rauning, Gerald. A Thousand Machines. A Concise Philosophy as Social Movement. Los Angeles: Semiotext(e), 2010.

Serres, Michel. The Natural Contract. Michigan: University of Michigan Press, 1995. DOl: https://doi.org/10.3998/mpub.9725.

Simondon, Gilbert. El Modo de Existencia de Los Objetos Técnicos. Buenos Aires: Prometeo Libros, 2007.

Simondon, Gilbert. Imaginación e invención. Buenos Aires: Cactus, 2013.

Simondon, Gilbert. La Individuación a La Luz de Las Nociones de Forma y de Información. Buenos Aires: Cactus, 2015.

Soriano, Carles. Antropoceno. Reproducción de Capital y Comunismo. Madrid: Maia Ediciones, 2021. 


\section{artnodes}

\section{CV}

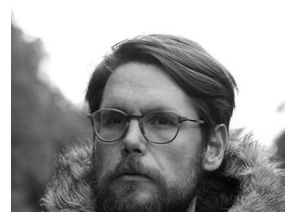

\section{Borja Muntadas}

Universitat Oberta de Catalunya

bmuntadasf@uoc.edu

Profesor colaborador en la UOC, de Filosofía en los Estudios de Artes y Humanidades y de Psicología Social en los de Psicología y Ciencias de la Educación. Miembro del grupo de investigación de la UOC MUSSOL. Ha sido profesor invitado en el máster de Derecho y en el de Biocombustibles en la UFU (Brasil). Miembro del Conselho editorial de LAECC, coordinador de la editorial LIBRANT y miembro del consejo editorial de la revista $A s$ trolabio. Posdoctorado en Filosofía y Derecho (UFU), doctor en Filosofía Contemporánea (UB), licenciado en Filosofía (UB) y diplomado en Ciencias Empresariales (UPC). Es coautor de La jaula del tiempo (2020) y autor de Inmediatez. Capitalismo y vidas aceleradas (2016).

https://orcid.org/0000-0001-6660-7567

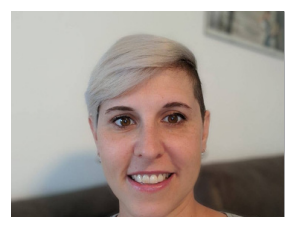

\section{Alba Torrents}

Universidad Autónoma de Barcelona

Universitat Oberta de Catalunya

albagtorrents@uoc.edu

Doctora en Filosofía por la Universidad Autónoma de Barcelona y en Comunicación Social por la Universidad Nacional de Córdoba. Actualmente, trabaja como docente en el Departamento de Filosofía de la UAB. También es profesora colaboradora del máster de Filosofía para los Retos Contemporáneos de la Universitat Oberta de Catalunya y miembro del grupo de investigación MUSSOL de la misma universidad. Durante su etapa doctoral trabajó como becaria del Consejo Nacional de Investigación Científica y Técnica (CONICET) y estuvo como investigadora en el Centro para la Investigación y el Estudio de la Cultura y la Sociedad (CIECS) en la UNC. Al final de su etapa doctoral le fue concedida una Japan Foundation Fellowship que le permitió trabajar como investigadora invitada en la Universidad de Kyoto Seika y el Museo Internacional de Manga de Kyoto.

https://orcid.org/0000-0002-0955-5024

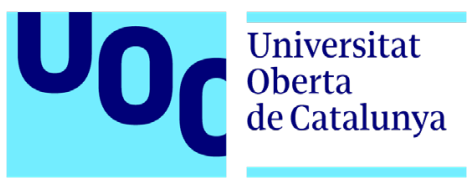

